\title{
Effects of clofazimine on planktonic and biofilm growth of Mycobacterium tuberculosis and Mycobacterium smegmatis
}

Maborwa T. Mothiba ${ }^{a}$, Ronald Anderson ${ }^{a}$, Bernard Fourie ${ }^{b}$, Willem A.

Germishuizen $^{a}$, Moloko C. Cholo ${ }^{\mathrm{a}, *}$

${ }^{a}$ Department of Immunology, Faculty of Health Sciences, University of Pretoria, Pretoria 0001, South Africa

${ }^{\mathrm{b}}$ Department of Medical Microbiology, Faculty of Health Sciences, University of Pretoria, Pretoria 0001, South Africa

Keywords:

Biofilm ; Clofazimine ; Planktonic ; Mycobacterium tuberculosis ; Mycobacterium smegmatis ; Minimum bactericidal concentration

* Corresponding author. Present address: Department of Immunology, P.O. Box 2034, Pretoria 0001, South Africa. Tel.: +27 12319 2162; fax: +27 123230732 .

E-mail address: moloko.cholo@up.ac.za (M.C. Cholo).

\section{ABSTRACT}

Mycobacteria form lipid-rich biofilms that restrict the efficacy of antimicrobial chemotherapy, possibly necessitating the use of lipophilic antibiotics. In the current study, the activity of one such agent, clofazimine, against Mycobacterium tuberculosis and Mycobacterium smegmatis planktonic cells and biofilms was investigated. Minimum inhibitory concentrations (MICs) of clofazimine were determined for planktonic cultures, whilst minimum bactericidal concentrations 
(MBCs) were determined for planktonic, biofilm-producing and biofilm-encased organisms using standard bacteriological procedures. The effects of clofazimine on biofilm formation and the stability of pre-formed biofilm were measured using a crystal violet-based spectrophotometric procedure. In the case of M. smegmatis, clofazimine was found to be active against planktonic phase (MICs and MBCs of 2.5 $\mathrm{mg} / \mathrm{L}$ and $>20 \mathrm{mg} / \mathrm{L}$, respectively) and biofilm-producing organisms (MBC of 2.5 $\mathrm{mg} / \mathrm{L})$; clofazimine demonstrated greater activity against $M$. tuberculosis, corresponding values of $0.06,5$ and $0.3 \mathrm{mg} / \mathrm{L}$. Although clofazimine inhibited biofilm production both by $M$. tuberculosis and $M$. smegmatis $(P<0.05$ at $\geq 0.07 \mathrm{mg} / \mathrm{L}$ and $\geq 0.3 \mathrm{mg} / \mathrm{L}$, respectively) and appeared to reduce the pre-formed $M$. tuberculosis biofilm, addition of antimicrobial agent to pre-existing biofilm matrices failed to kill biofilm-encased organisms. In conclusion, clofazimine is more effective against $M$. tuberculosis than against M. smegmatis, exhibiting bactericidal activity both for actively growing and slowly replicating bacilli but not for non-replicating organisms of both species.

\section{Introduction}

Unlike the biofilms of most bacteria, which consist of an assemblage of exopolysaccharides, lipids, proteins and DNA, those of mycobacteria have a particularly high lipid content, including glycolipids and mycolic acids [1-3]. Mycobacterial subpopulations resident in biofilm matrices consist of planktonic (aerated, exponentially or actively growing) and sessile (slowly/non-replicating, dormant, persistent) bacteria that vary with respect to antibiotic susceptibility, the former being generally sensitive and the latter resistant [2-4]. Notwithstanding the slowly/non-replicating state, resistance of the sessile population to antimicrobial 
agents is also attributable to poor penetration of the biofilm by ostensibly effective antibiotics [5]. In the setting of pulmonary tuberculosis (TB), the sessile organisms are insulated in sac-like granuloma lesions, somewhat similar to encasement in biofilm observed in in vitro cultures [6-8]. During TB chemotherapy with rifampicin and isoniazid, planktonic bacteria are killed rapidly (within 2 weeks), whilst eradication of sessile organisms necessitates extended exposure to higher concentrations of these agents $[1,4,9]$. Clearly, antibiotics that penetrate the biofilm and/or inhibit its formation $[10,11]$ have the potential to improve the efficacy of TB chemotherapy.

The antimycobacterial riminophenazine agent clofazimine is categorised by the World Health Organization (WHO) as a last-resort option (group 5 drug) in the treatment of multidrug-resistant TB (MDR-TB), largely because of its poor pharmacokinetic properties $[12,13]$. However, this antibiotic possesses several properties that may enable it to target both biofilm-forming as well as biofilminsulated organisms, including those that are MDR [12-14]. Foremost amongst these are its lipophilicity and low-level resistance profile, as well as recently described inhibitory activity against mycobacterial persisters [15-18]. To address this issue, this study was undertaken with the primary objectives of determining: (i) the minimum inhibitory concentrations (MICs) and minimum bactericidal concentrations (MBCs) of clofazimine against actively growing planktonic and slowly replicating biofilm-producing mycobacteria as well as non-replicating biofilm-encased organisms; and (ii) the inhibitory effects of clofazimine both on biofilm formation and the structural resilience of pre-formed biofilm. 


\section{Materials and methods}

\subsection{Strains and growth media}

Mycobacterium tuberculosis H37Rv ATCC 25618 and Mycobacterium smegmatis $M^{2} 155$ laboratory strains were used in this study. $7 \mathrm{H} 10$ agar (Difco: Becton Dickinson (BD) Diagnostics, Sparks, Maryland, USA) containing $0.5 \%$ glycerol/10\% oleic acid-dextrose-catalase (OADC) (BD Diagnostics, Sparks, Maryland, USA) as well as $7 \mathrm{H} 9$ broth (Difco) containing $0.2 \%$ glycerol/10\% OADC/0.05\% Tween 80 were prepared following the manufacturers' instructions, whilst Sauton broth was prepared as described previously [1].

\subsection{Chemicals, reagents and antibiotics}

Unless otherwise stated, all other chemicals and reagents, including clofazimine, were purchased from Sigma Chemical Co. (St Louis, MO, USA). Clofazimine was dissolved in dimethyl sulphoxide (DMSO) and was used at concentrations ranging from $0.01 \mathrm{mg} / \mathrm{L}$ to $20 \mathrm{mg} / \mathrm{L}$. The final concentration of DMSO in the drug-containing and control systems was $1 \%$, and solvent controls were included in all experiments.

\subsection{Inoculum preparation}

Mycobacterium tuberculosis and $M$. smegmatis were inoculated into $7 \mathrm{H} 9$ broth and were incubated at $37^{\circ} \mathrm{C}$ for 7 days or $24 \mathrm{~h}$ under stirring conditions, respectively. Thereafter, the cultures were centrifuged at $3500 \times g$ for $10 \mathrm{~min}$ at room temperature and the supernatants were discarded. The pellets were washed twice, re-suspended 
in Sauton broth and the optical density at $540 \mathrm{~nm}$ was adjusted to 0.6 , yielding ca. $10^{7}-10^{8} \mathrm{CFU} / \mathrm{mL}$.

\subsection{Minimum inhibitory concentration determination}

The MICs of clofazimine for M. tuberculosis and M. smegmatis were determined using broth and plate dilution procedures in a BACTEC TB system (Becton Dickinson Co., Maryland, USA) and on 7H10 plates, respectively, based on the proportion method as described previously $[19,20]$. The clofazimine concentrations used ranged from $0.01 \mathrm{mg} / \mathrm{L}$ to $5 \mathrm{mg} / \mathrm{L}$. For $M$. tuberculosis, the procedure used was as described previously [19]. In the case of $M$. smegmatis, the various concentrations of clofazimine were incorporated into $7 \mathrm{H} 10$ agar plates. One set of drug-free and all drug-containing plates were inoculated with $10^{4} \mathrm{CFU} / \mathrm{mL}$, whilst another set of drug-free plates, serving as controls, was inoculated with $100 \times$ dilution of the inoculum $\left(10^{2} \mathrm{CFU} / \mathrm{mL}\right)$. The plates were incubated at $37^{\circ} \mathrm{C}$ for $72 \mathrm{~h}$ to allow for the appearance of colonies. The lowest concentration of the drug that yielded fewer colonies than those that grew on the $100 \times$ diluted controls was regarded as the MIC.

\subsection{Planktonic and biofilm culture preparation}

Approximately $10^{5} \mathrm{CFU} / \mathrm{mL}$ were inoculated into tissue culture plates containing $7 \mathrm{H} 9$ or Sauton broth with no detergent for planktonic or biofilm cultures, respectively. For M. tuberculosis, $1.5 \mathrm{~mL}$ volumes of bacterial cultures were added to the centre wells of 24-well tissue culture plates (Greiner Bio-One GmbH, Frickenhausen, Germany), whilst peripheral wells were filled with the same volume of sterile distilled water to 
prevent desiccation. In the case of $M$. smegmatis, $5 \mathrm{~mL}$ volumes of bacterial cultures were added to the wells of 6-well tissue culture plates (Greiner Bio-One GmbH, Frickenhausen, Germany). All cultures were thoroughly mixed and incubated at 37 ${ }^{\circ} \mathrm{C}$ in the dark.

Planktonic culture plates were incubated for 10 days or $24 \mathrm{~h}$ with frequent shaking, whilst the corresponding biofilm culture plates were wrapped with Parafilm ${ }^{\circledR}$ and were incubated without shaking for 10 weeks or 5 days for biofilm formation and for 5 weeks or 5 days post biofilm development for pre-formed biofilm cultures for $M$. tuberculosis and M. smegmatis, respectively. Biofilm formation resulted in the formation of a white layer on the surface of the culture medium $[1,21,22]$.

The rates of growth of the bacteria were determined by sampling, diluting and plating the cultures every $24 \mathrm{~h}$ and $6 \mathrm{~h}$ for $M$. tuberculosis and M. smegmatis planktonic organisms, respectively, and bi-/weekly or daily for biofilm bacilli for each mycobacterial species, and monitoring thereafter for the appearance of colonies, which were compared with the number of viable bacteria in the initial inoculum.

\subsection{Minimum bactericidal concentration determination and rate of killing}

Clofazimine MBCs were determined for planktonic and biofilm cultures of both mycobacterial species. Varying concentrations of clofazimine were added to one set of wells, whilst drug-free control systems received DMSO. Planktonic organisms were treated with clofazimine $(0.3-20 \mathrm{mg} / \mathrm{L})$ for 10 days or $24 \mathrm{~h}$, whilst the biofilmforming bacilli were treated $(0.01-5 \mathrm{mg} / \mathrm{L})$ for 10 weeks or 5 days for $M$. tuberculosis and $M$. smegmatis, respectively. In the case of biofilm-encased bacilli, the 
corresponding treatment $(0.15-20 \mathrm{mg} / \mathrm{L})$ times were 5 weeks and 5 days post biofilm development. The number of planktonic bacilli was determined by sampling each well and dilutions plated on $7 \mathrm{H} 10$ agar plates, followed by incubation at $37^{\circ} \mathrm{C}$ in the dark for 3 weeks or $72 \mathrm{~h}$ for the appearance of colonies for M. tuberculosis or $M$. smegmatis, respectively. The number of clofazimine-treated biofilm-producing bacilli was determined by adding $100 \mu \mathrm{L}$ of $0.2 \%$ Tween 80 to culture wells followed by incubation on a shaker at $37^{\circ} \mathrm{C}$ for $24 \mathrm{~h}$ or $1 \mathrm{~h}$ for $M$. tuberculosis and $M$. smegmatis, respectively, to solubilise biofilm. The cultures were sampled and plated as described previously for planktonic organisms. The number of clofazimine-treated biofilm-encased bacilli was determined for 5 weeks or 5 days following addition of the antimicrobial agents for $M$. tuberculosis or $M$. smegmatis, respectively.

The rate of clofazimine-mediated killing of the various bacterial populations was determined by evaluating the MBCs daily or every $6 \mathrm{~h}$ for planktonic organisms, and bi-/weekly or daily for biofilm-producing and biofilm-encased $M$. tuberculosis or $M$. smegmatis, respectively. The MBC was regarded as the lowest concentration of clofazimine showing $\geq 2$ log reduction in CFU/mL of the initial inoculum (Day 0) [20].

\subsection{Biofilm quantification}

Biofilms were quantitated using a crystal violet-based staining procedure [23]. Supernatants were removed and the residual biofilm biomasses were washed twice with distilled water and were air-dried. Crystal violet (1\%) was added to each well and was incubated for $30 \mathrm{~min}$ at room temperature. Unbound dye was removed by washing with distilled water and the wells were air-dried. The residue was dissolved 
and the crystal violet was extracted in $70 \%$ ethanol, diluted and the optical density at $570 \mathrm{~nm}$ was measured using a Unicam Heגios- $\gamma$ UV spectrophotometer (Thermo Scientific, Waltham, MA, USA).

\subsection{Statistical analyses}

Results are expressed as the mean \pm standard error of the mean for each series of experiments. Statistical analysis was performed using GraphPad InStat 3 (GraphPad Software Inc., La Jolla, CA). All figures were plotted using GraphPad Prism v.5 (GraphPad Software Inc.).

\section{Results}

\subsection{Minimum inhibitory concentrations of clofazimine for planktonic bacilli}

Using broth and plate dilution methods, clofazimine demonstrated dose-related inhibition of the growth of $M$. tuberculosis and M. smegmatis, with MICs of $0.06 \mathrm{mg} / \mathrm{L}$ and $2.5 \mathrm{mg} / \mathrm{L}$, respectively.

\subsection{Minimum bactericidal concentrations of clofazimine for planktonic bacilli} MBCs of clofazimine for planktonic bacilli are shown in Fig. 1. Both for $M$. tuberculosis and $M$. smegmatis planktonic cultures, the resident population consists of exponentially growing bacilli, as they replicate faster than the biofilm-producing and biofilm-encased populations. The number of bacteria in the control wells increased from $1.2 \times 10^{5} \pm 2.9 \times 10^{4} \mathrm{CFU} / \mathrm{mL}$ to $1.4 \times 10^{9} \pm 1.6 \times 10^{8} \mathrm{CFU} / \mathrm{mL}$ in 10 
(a)

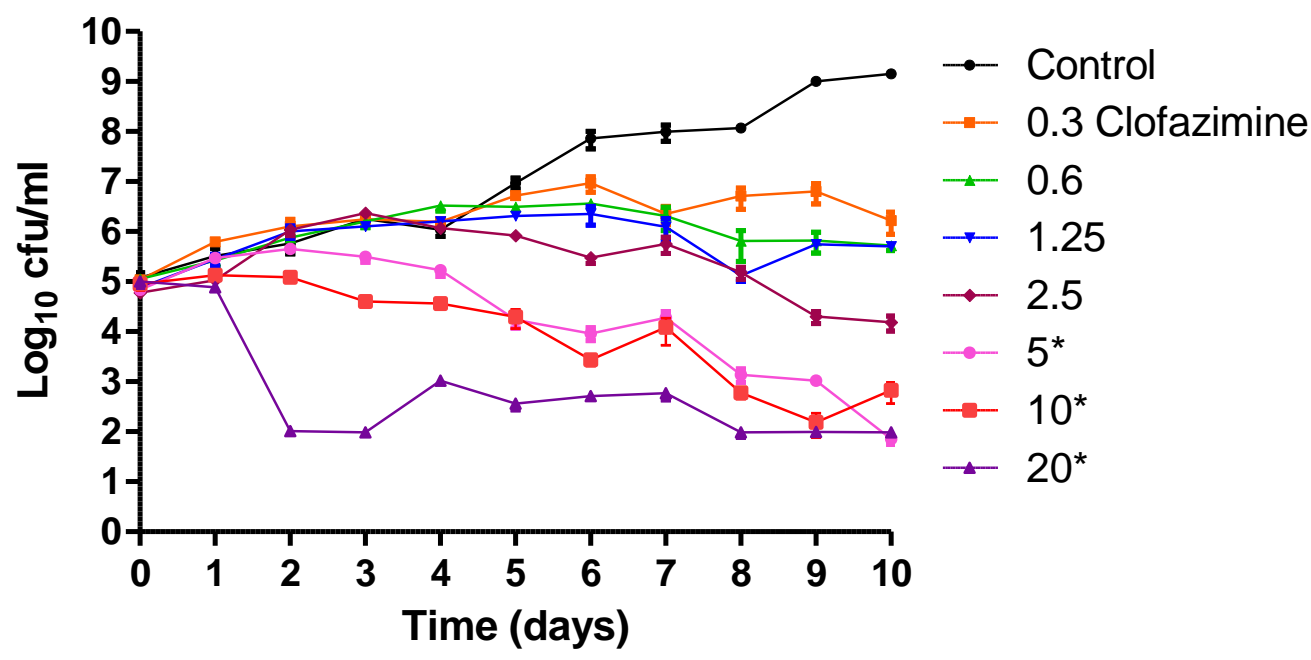

(b)

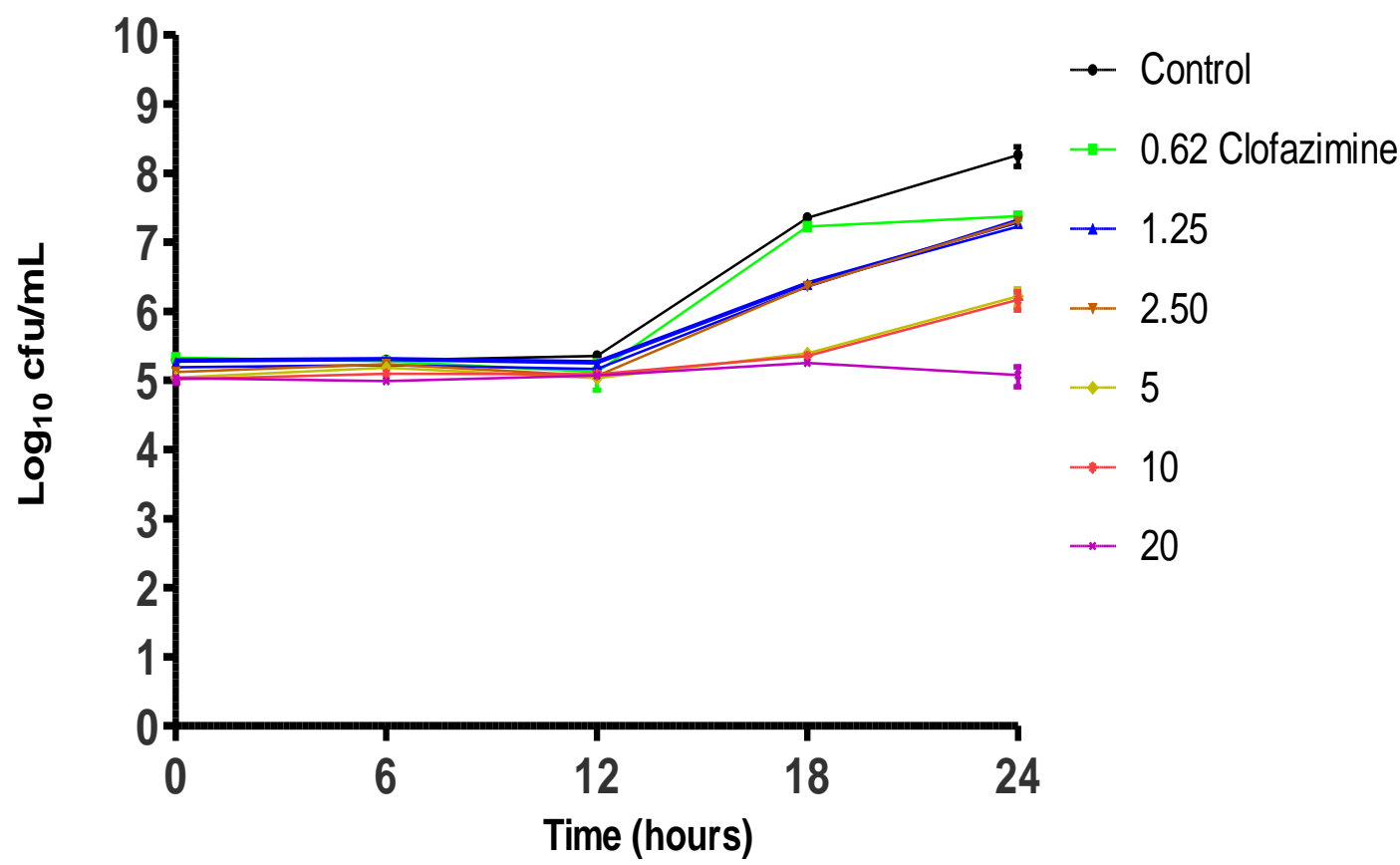

Fig. 1. Clofazimine (0.3-20 mg/L) minimum bactericidal concentrations (MBCs) and time-kill curves for planktonic bacilli of (a) Mycobacterium tuberculosis and (b) Mycobacterium smegmatis. The results are for three separate experiments performed in duplicate for each concentration of clofazimine and are presented as the mean \pm standard error of the mean. (a) For $M$. tuberculosis, the number of bacteria on Day 0 was $1.2 \times 10^{5} \pm 2.9 \times 10^{4} \mathrm{CFU} / \mathrm{mL}$ and the maximum growth achieved in the control on Day 10 was $1.4 \times 10^{9} \pm 1.6 \times 10^{8} \mathrm{CFU} / \mathrm{mL}$. The MBC was achieved at $5 \mathrm{mg} / \mathrm{L}^{\star}$. The rate of bacterial killing for each concentration of the antibiotic was determined daily for 10 days. (b) For M. smegmatis, the number of bacteria at $0 \mathrm{~h}$ was $2 \times$ $10^{5} \pm 4.7 \times 10^{3} \mathrm{CFU} / \mathrm{mL}$ and the maximum growth achieved in the control at $24 \mathrm{~h}$ was $1.8 \times 10^{8} \pm 5.8 \times 10^{7} \mathrm{CFU} / \mathrm{mL}$. No MBC was achieved. The rate of killing for each concentration of the antibiotic was determined at 6-h time points for $24 \mathrm{~h}$. 
days and from $2 \times 10^{5} \pm 4.7 \times 10^{3} \mathrm{CFU} / \mathrm{mL}$ to $1.8 \times 10^{8} \pm 5.8 \times 10^{7} \mathrm{CFU} / \mathrm{mL}$ in $24 \mathrm{~h}$ for M. tuberculosis and M. smegmatis, respectively.

The MBC of clofazimine against $M$. tuberculosis planktonic organisms was $5 \mathrm{mg} / \mathrm{L}$ $\left(1.3 \times 10^{3} \pm 2 \times 10^{2} \mathrm{CFU} / \mathrm{mL}\right)$ on Day $8,10 \mathrm{mg} / \mathrm{L}\left(2.7 \times 10^{3} \pm 6.7 \times 10^{2} \mathrm{CFU} / \mathrm{mL}\right)$ on Day 6 and $20 \mathrm{mg} / \mathrm{L}\left(1.3 \times 10^{2} \pm 20 \mathrm{CFU} / \mathrm{mL}\right)$ on Day 2. No lethal effect of clofazimine was achieved against $M$. smegmatis planktonic bacilli.

\subsection{Activity of clofazimine against biofilm-producing mycobacterial bacilli}

The activity of clofazimine against biofilm-producing mycobacterial bacilli is shown in Fig. 2. Both for M. tuberculosis and M. smegmatis biofilm-producing cultures, the resident population consists predominantly of slowly replicating bacilli, as their replication rate was slower than that of planktonic organisms. The number of biofilmproducing bacteria in the control wells increased from $1.3 \times 10^{5} \pm 3 \times 10^{3} \mathrm{CFU} / \mathrm{mL}$ to $6.2 \times 10^{6} \pm 2.6 \times 10^{6} \mathrm{CFU} / \mathrm{mL}$ in 10 weeks and from $2.6 \times 10^{5} \pm 3.7 \times 10^{4} \mathrm{CFU} / \mathrm{mL}$ to $2.3 \times 10^{8} \pm 7.2 \times 10^{6} \mathrm{CFU} / \mathrm{mL}$ in 5 days for M. tuberculosis and M. smegmatis, respectively.

The MBC of clofazimine for biofilm-producing M. tuberculosis was $0.15 \mathrm{mg} / \mathrm{L}$ at Week 2, resulting in a $3 \log \left(2.9 \times 10^{2} \pm 39 \mathrm{CFU} / \mathrm{mL}\right)$ reduction in $\mathrm{CFU} / \mathrm{mL}$. However, at Week 4 the number of bacilli in the wells treated with $0.15 \mathrm{mg} / \mathrm{L}$ clofazimine began to increase but stabilised at $0.3 \mathrm{mg} / \mathrm{L}$. For M. smegmatis, the MBC was achieved at $2.5 \mathrm{mg} / \mathrm{L}$ on Day 5 and at $5 \mathrm{mg} / \mathrm{L}$ on Day 3 . 
(a)

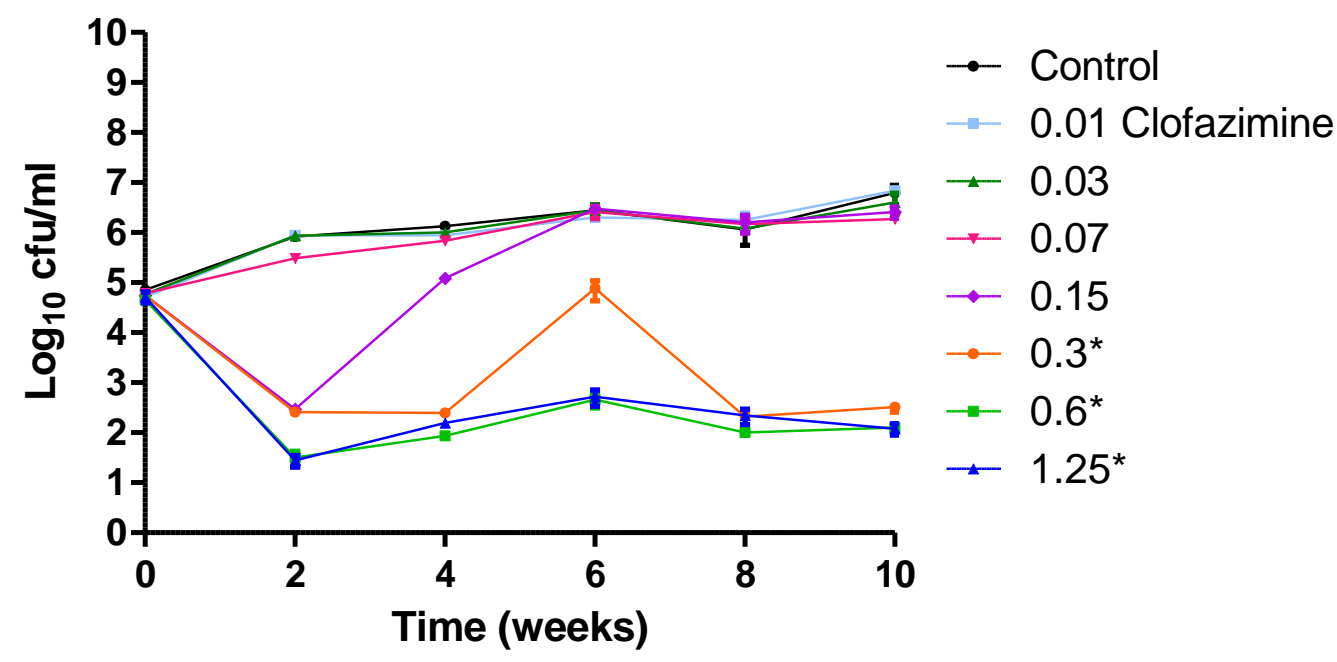

(b)

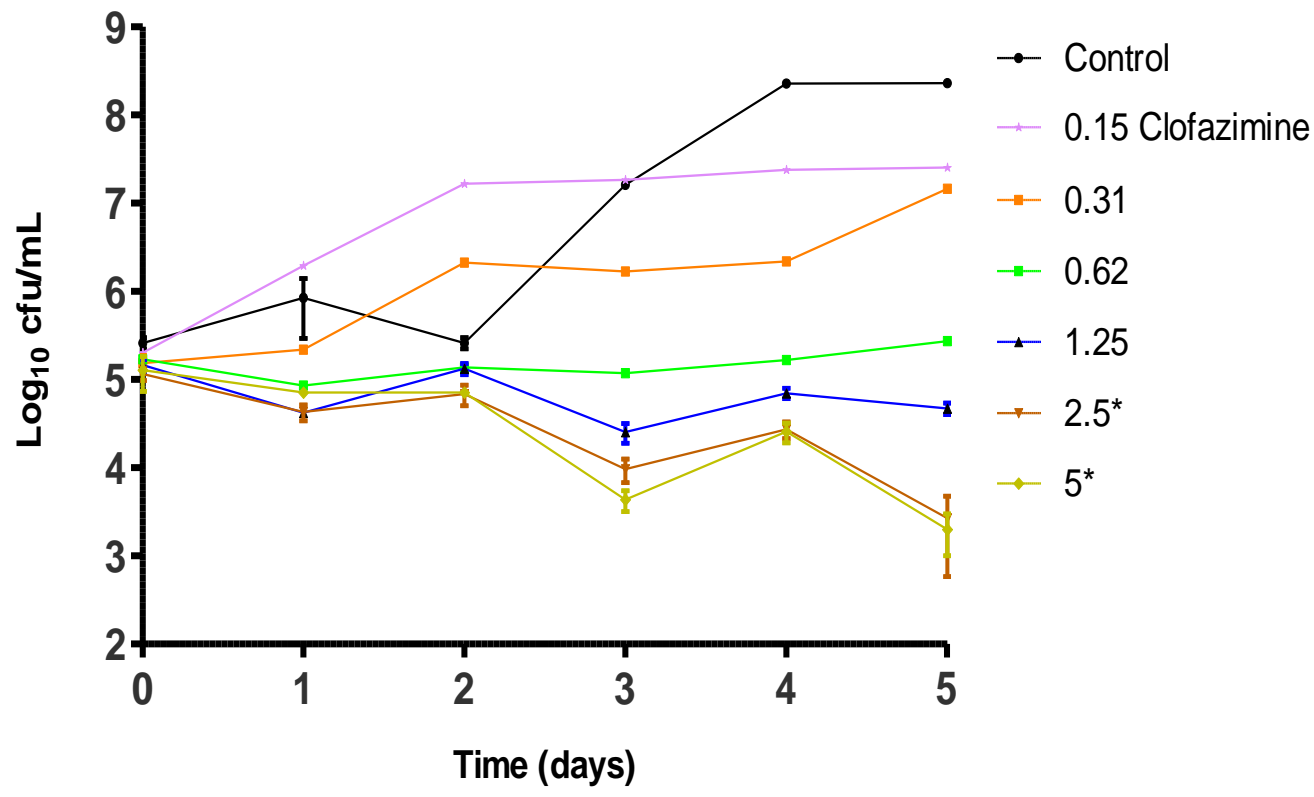

Fig. 2. Clofazimine $(0.01-5 \mathrm{mg} / \mathrm{L})$ minimum bactericidal concentrations (MBCs) and time-kill curves for biofilm-producing bacilli of (a) Mycobacterium tuberculosis and (b) Mycobacterium smegmatis. The results are for three separate experiments performed in duplicate for each concentration of clofazimine and are presented as the mean \pm standard error of the mean. (a) For $M$. tuberculosis, the number of bacteria at Week 0 was $1.3 \times 10^{5} \pm 3 \times 10^{3} \mathrm{CFU} / \mathrm{mL}$ and the maximum growth achieved in the control at Week 10 was $6.2 \times 10^{6} \pm 2.6 \times 10^{6} \mathrm{CFU} / \mathrm{mL}$. The MBC was achieved at $0.3 \mathrm{mg} / \mathrm{L}^{\star}$. The rate of bacterial killing for each concentration of the antibiotic was determined biweekly for 10 weeks. (b) For M. smegmatis, the number of bacteria at Day 0 was $2.6 \times 10^{5} \pm 3.7 \times 10^{4} \mathrm{CFU} / \mathrm{mL}$ and the maximum growth achieved in the control at Day 5 was $2.3 \times 10^{8} \pm 7.2 \times 10^{6}$ $\mathrm{CFU} / \mathrm{mL}$. The MBC was achieved at $2.5 \mathrm{mg} / \mathrm{L}^{*}$. The rate of killing for each concentration was determined daily for 5 days. 
a)

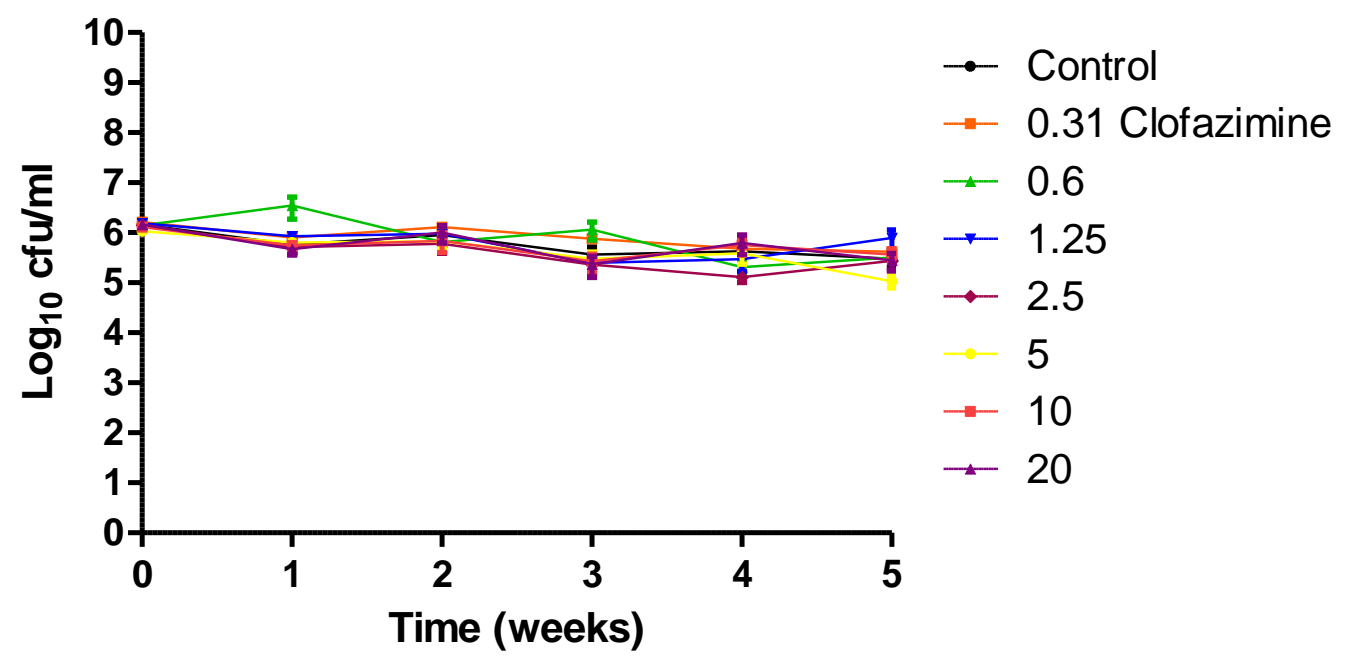

(b)

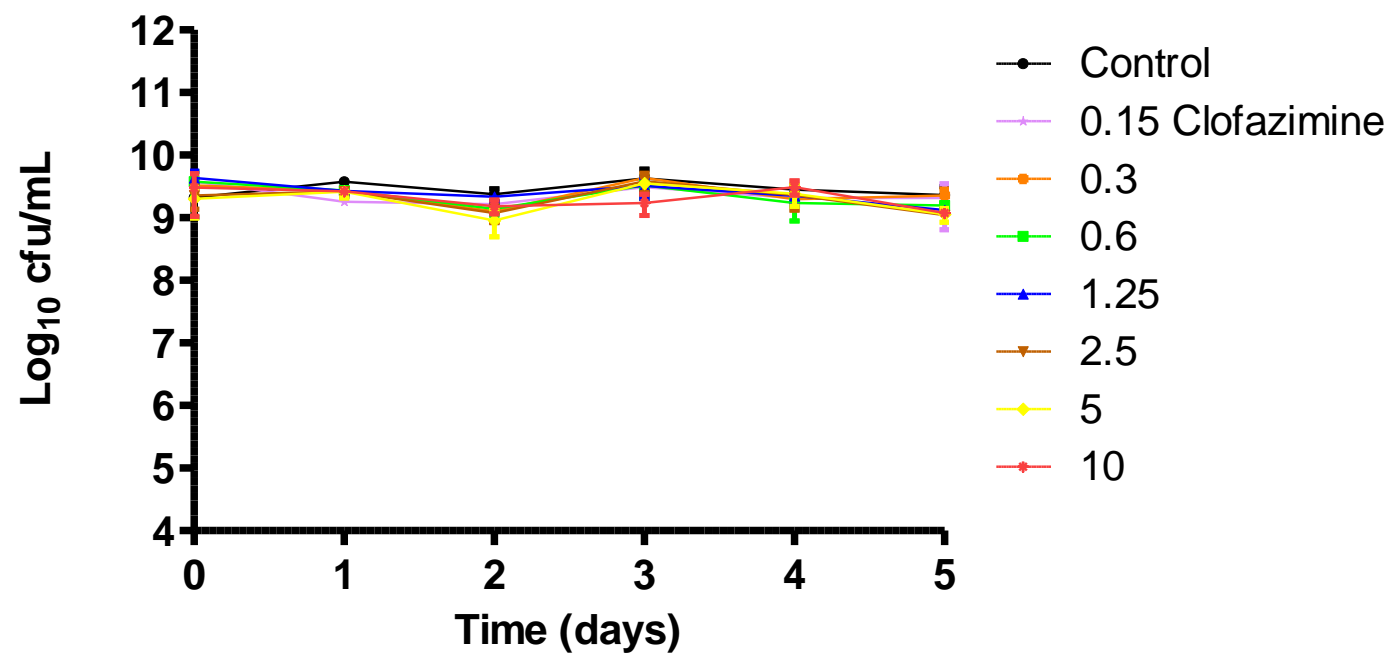

Fig. 3. Clofazimine $(0.15-20 \mathrm{mg} / \mathrm{L})$ minimum bactericidal concentrations (MBCs) and time-kill curves for biofilm-encased bacilli of (a) Mycobacterium tuberculosis and (b) Mycobacterium smegmatis. The results are for three separate experiments performed in duplicate for each concentration of clofazimine and are presented as the mean \pm standard error of the mean. (a) For M. tuberculosis, the number of bacteria in the control cultures at Week 0 was $1.5 \times 10^{6} \pm 3.7 \times 10^{5} \mathrm{CFU} / \mathrm{mL}$ and did not increase until Week 5 post clofazimine treatment. No MBC of clofazimine was achieved against biofilm-encased $M$. tuberculosis bacilli. The rate of bacterial killing for each concentration of the antibiotic was determined weekly for 5 weeks post clofazimine treatment. (b) For M. smegmatis, the number of bacteria at Day 0 was $2.1 \times 10^{9} \pm 1.1 \times 10^{9} \mathrm{CFU} / \mathrm{mL}$ and remained stable until Day 5 post clofazimine treatment. No MBC was achieved for biofilm-encased $M$. smegmatis bacilli. The rate of bacterial killing of each concentration of the antibiotic was determined daily for 5 days post clofazimine treatment. 


\subsection{Activity of clofazimine against biofilm-encased mycobacteria}

The activity of clofazimine against biofilm-encased mycobacteria is shown in Fig. 3. Following biofilm formation, the biofilm-encased bacteria were treated with clofazimine and the numbers of surviving organisms were measured weekly or daily thereafter for 5 weeks or 5 days for M. tuberculosis and M. smegmatis, respectively. In the control wells, the numbers of bacteria remained unchanged at concentrations of $1.5 \times 10^{6} \pm 3.7 \times 10^{5} \mathrm{CFU} / \mathrm{mL}$ and $2.1 \times 10^{9} \pm 1.1 \times 10^{9} \mathrm{CFU} / \mathrm{mL}$ for $M$. tuberculosis and $M$. smegmatis, respectively. The observed absence of an increase in the number of bacilli in the biofilm-encased populations is consistent with the existence of predominantly non-replicating organisms that were unresponsive to clofazimine.

\subsection{Effects of clofazimine on mycobacterial biofilm formation}

The effects of clofazimine on mycobacterial biofilm formation are shown in Fig. 4. Biofilm formation both by $M$. tuberculosis and $M$. smegmatis was inhibited in a dosedependent manner by clofazimine, attaining statistical significance at $0.07 \mathrm{mg} / \mathrm{L}$ and $0.3 \mathrm{mg} / \mathrm{L}$, respectively. The corresponding values for complete inhibition were 0.15 $\mathrm{mg} / \mathrm{L}$ and $0.6 \mathrm{mg} / \mathrm{L}$. It was noted that clofazimine retained a red colouration during treatment of these cultures, indicating retention of the drug in the active, oxidised form during treatment of biofilm-forming cultures consistent with adequate aeration. 
(a)

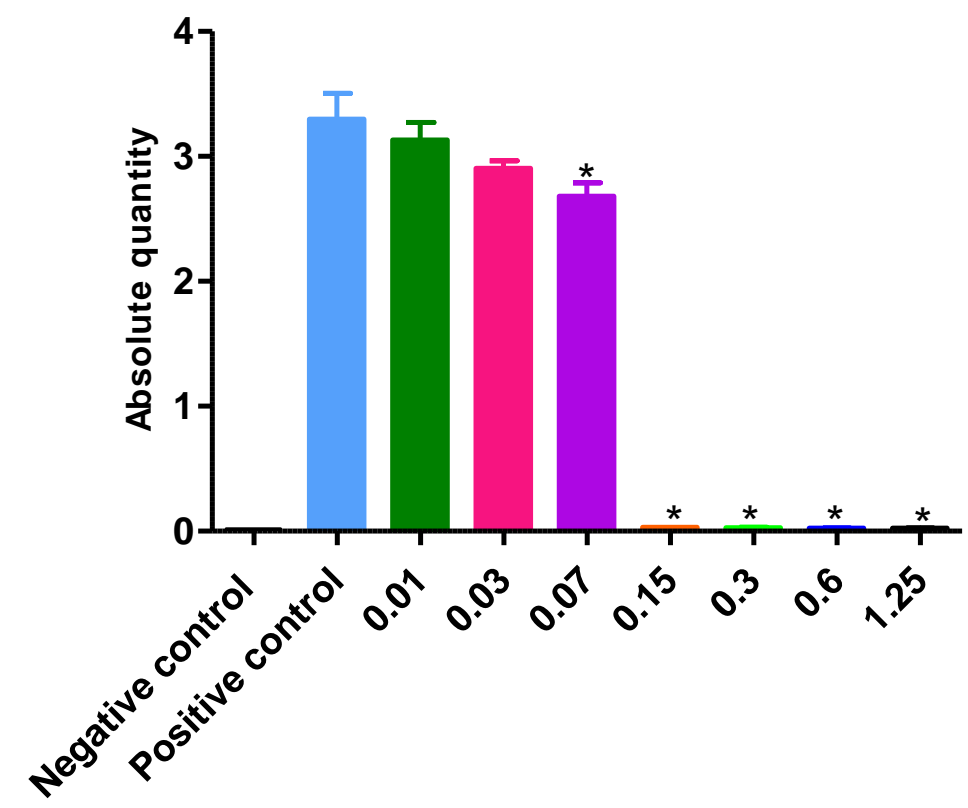

(b)

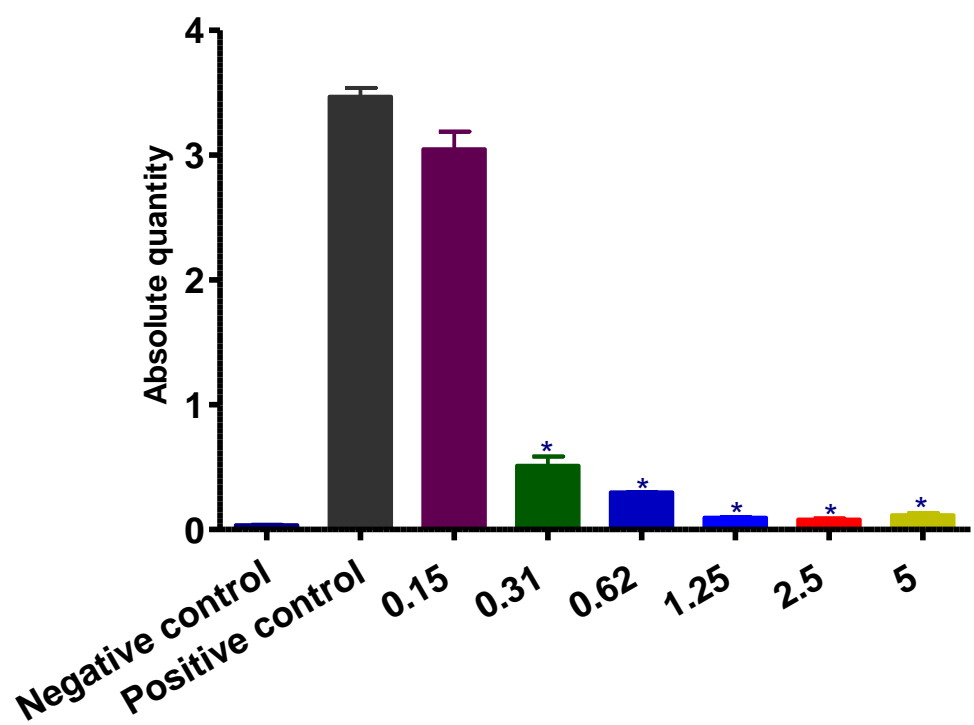

Fig. 4. Effects of clofazimine on biofilm formation by (a) Mycobacterium tuberculosis and (b) Mycobacterium smegmatis. The results are for three separate experiments performed in duplicate for each concentration of the antibiotic $(0.01-5 \mathrm{mg} / \mathrm{L})$ and are presented as the mean \pm standard error of the mean. ${ }^{*}$ Statistically significant difference $(P<0.05)$ in comparison with the positive control. The negative control is the absolute value for the growth medium without cells, whilst the positive control is the absolute value for the drug-free control system as described in the Materials and Methods section 2.6. 


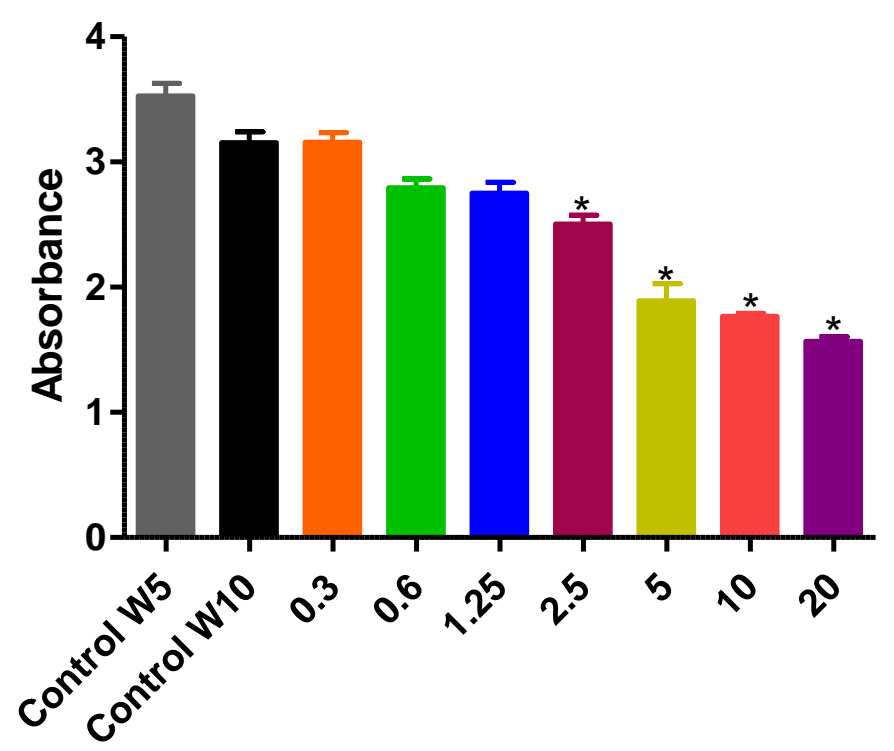

\section{Clofazimine concentration $\mathrm{mg} / \mathrm{L}$}

Fig. 5. Effects of clofazimine on pre-formed biofilm of Mycobacterium tuberculosis. The results are for three separate experiments performed in duplicate for each concentration of the antibiotic and are presented as the mean \pm standard error of the mean. * Statistically significant difference $(P<0.05)$ in comparison with the control W10. Control W5 represents the absolute amount of pre-formed biofilm in the control wells on Week 5 post biofilm development, which is regarded as Week 0 for antibiofilm activity of clofazimine, whilst control W10 represents the amount of pre-formed biofilm 5 weeks post clofazimine treatment. Statistical differences for drug-treated systems were determined in comparison with control W10.

\subsection{Effects of clofazimine on pre-formed mycobacterial biofilm biomass}

The effects of clofazimine on pre-formed mycobacterial biofilm biomass are shown in Fig. 5. In the case of M. tuberculosis, addition of clofazimine to pre-formed biofilm resulted in a reduction in the biofilm mass that was statistically significant at $\geq 2.5$ $\mathrm{mg} / \mathrm{L}$ but was incomplete even when the concentration of clofazimine was increased. In the case of $M$. smegmatis, the biofilm biomass was unaffected by the addition of the antimicrobial agent (data not shown). Interestingly, clofazimine added to preformed M. smegmatis biofilm, but not to M. tuberculosis biofilm, became colourless consistent with very poor aeration. 


\section{Discussion}

The results of the current study have demonstrated that clofazimine, a lipophilic, cationic, amphiphilic antimycobacterial agent, exhibits differential activities against actively growing and slowly replicating as well as non-replicating $M$. tuberculosis and M. smegmatis bacilli.

In the case of exponentially growing $M$. tuberculosis bacilli in planktonic cultures, the MICs and MBCs for clofazimine were $0.06 \mathrm{mg} / \mathrm{L}$ and $5 \mathrm{mg} / \mathrm{L}$, respectively. The corresponding clofazimine MIC for M. smegmatis was $2.5 \mathrm{mg} / \mathrm{L}$, with no achievable $\mathrm{MBC}$, possibly due to the insolubility of the antimicrobial agent at concentrations $>20$ $\mathrm{mg} / \mathrm{L}$. However, it should also be noted that the exponentially growing cells were generated in a different medium (7H9) from that for biofilm production and the differences in effects of the antibiotic may be related not only to growth rates but also to the culture conditions.

Of the three types of microbial populations tested, the slowly replicating biofilmproducing bacilli of both mycobacterial species were found to be most susceptible to the bactericidal action of clofazimine, with MBCs of $0.3 \mathrm{mg} / \mathrm{L}$ and $2.5 \mathrm{mg} / \mathrm{L}$ for $M$. tuberculosis and M. smegmatis, respectively. Exposure to clofazimine also resulted in dose-related inhibition of biofilm formation that achieved statistical significance at concentrations of $0.07 \mathrm{mg} / \mathrm{L}$ and $0.3 \mathrm{mg} / \mathrm{L}$ for $M$. tuberculosis and $M$. smegmatis, respectively, probably secondary to inhibition of bacterial growth.

Addition of clofazimine to biofilm-encased, non-replicating bacilli of both mycobacterial species did not, however, affect survival on subsequent release of 
these organisms from the biofilm matrix. The failure of clofazimine in this setting may result from insensitivity of non-replicating bacilli to the antibiotic and/or the impenetrable nature of the biofilm mass.

These findings are essentially in agreement with a recent study reported by Irwin et al. who described the differential efficacy of clofazimine monotherapy in several murine models of experimental pulmonary TB [24]. Clofazimine was found to be most effective against the rapidly growing, intracellular bacilli in multifocal, coalescing lesions in the lungs of BALB/c mice as well as extracellular bacilli in the initiation phase of granuloma formation in C3HeB/FeJ mice [24]. However, clofazimine was ineffective against extracellular bacilli encased in the well established, hypoxic, caseous, necrotic granulomas in the lungs of $\mathrm{C} 3 \mathrm{HeB} / \mathrm{FeJ}$ mice [24].

The findings of the current study taken together with those of Irwin et al. [24] and others $[16,25]$ suggest that clofazimine and other antimycobacterial agents may be most effective in well aerated environments, seemingly consistent with the involvement of endogenously generated reactive oxygen species in antimicrobial activity. However, alternative mechanisms of clofazimine-mediated antimicrobial activity, probably also negated by dormancy, have also been proposed [15,19].

Irrespective of mechanisms of antimicrobial activity, of which there may be several, a number of clinical trials support the inclusion of clofazimine in the multidrug therapy of drug-resistant TB. When used throughout the entire treatment period, addition of clofazimine has been reported to improve cure rates in the setting of a shorter 
duration of treatment $[14,26,27]$. Importantly, similar treatment outcomes both for MDR-TB and extremely drug-resistant TB (XDR-TB) cases have been reported, probably reflecting the low level of resistance to clofazimine [28]. Based on these findings, the WHO has recommended that clofazimine be included in the multidrug therapy of XDR-TB [29]. It is noteworthy, however, that clofazimine has failed to demonstrate early bactericidal activity in the clinical setting, consistent with a relatively slow onset of antimicrobial action [18,19,30].

In conclusion, the findings of the current study have demonstrated that clofazimine is active against planktonic phase and slowly replicating $M$. tuberculosis but is ineffective against non-replicating, biofilm-encased bacilli. This limitation underscores the importance of combination chemotherapy of TB targeting the various phases of bacterial growth.

Funding: This work was supported by the South African Medical Research Council.

Competing interests: None declared.

Ethical approval: Not required.

\section{References}

[1] Ojha AK, Baughn AD, Sambandon D, Hsu T, Trivelli X, Guerardel Y, et al. Growth of Mycobacterium tuberculosis biofilms containing free mycolic acids and harbouring drugtolerant bacteria. Mol Microbiol 2008;69:164-74. 
[2] Ojha AK, Thivelli X, Guerardel Y, Kremer L, Hatfull GF. Enzymatic hydrolysis of trehalose dimycolate releases free mycolic acids during mycobacterial growth in biofilms. J Biol Chem 2010;285:17380-9.

[3] Pang JM, Layre E, Sweet L, Sherrid A, Moody DB, Ojha A, et al. The polyketide Pks1 contributes to biofilm formation in Mycobacterium tuberculosis. J Bacteriol 2012;194:715-21.

[4] McNabe M, Tennant R, Danelishvili L, Young L, Bermidez LE. Mycobacterium avium ssp. hominissius biofilm is composed of distinct phenotypes and influenced by the presence of antimicrobials. Clin Microbiol Infect 2011;17:697-703.

[5] Islam MS, Richards JP, Ojha AK. Targeting drug tolerance in mycobacteria: a perspective from mycobacterial biofilms. Expert Rev Anti Infect Ther 2012;10:1055-66.

[6] Saunders BM, Cooper AM. Restraining mycobacteria: role of granuloma in mycobacterial infections. Immunol Cell Biol 2000;78:334-41.

[7] Lenaerts AJ, Hoff D, Aly S, Ehlers S, Andries K, Cantarero L, et al. Location of persisting mycobacteria in a guinea pig model of tuberculosis revealed by r207910. Antimicrob Agents Chemother 2007;51:3338-45.

[8] Harper J, Skerry C, Davis SL, Tasneen R, Weir M, Kramnik I, et al. Mouse model of necrotic tuberculosis granulomas develops hypoxic lesions. J Infect Dis 2012;205:595-602.

[9] Feldman C, Anderson R. Antibiotic resistance of pathogens causing community-acquired pneumonia. Semin Respir Crit Care Med 2012;33:232-43.

[10]Beckloff N, Laube D, Castro T, Furgang D, Park S, Perlin D, et al. Activity of an antimicrobial peptide mimetic against planktonic and biofilm cultures of oral pathogens. Antimicrob Agents Chemother 2007;51:4125-32.

[11] Findlay B, Zhanel GG, Schweizer F. Cationic amphiphiles, a new generation of antimicrobials inspired by the natural antimicrobial peptide scaffold. Antimicrob Agents Chemother 2010;54:4049-58.

[12] Cholo MC, Steel HC, Fourie PB, Germishuizen WA, Anderson R. Clofazimine: current status and future prospects. J Antimicrob Chemother 2012;67:290-8.

[13] Dooley KE, Obuku EA, Durakovic N, Belitsky V, Mitnick C, Nuermberger EL. World Health Organization group 5 drugs for the treatment of drug-resistant tuberculosis: unclear efficacy or untapped potential? J Infect Dis 2013;207:1352-8. 
[14] Van Deun A, Maug AK, Salim MA, Das PK, Sarker MR, Daru P, et al. Short, highly effective and inexpensive standardized treatment of multidrug-resistant tuberculosis. Am J Respir Crit Care Med 2010;182:684-92.

[15] Cho SH, Warit S, Wan B, Hwang CH, Pauli GF, Franzblau SG. Low-oxygen-recovery assay for high-throughput screening of compounds against nonreplicating Mycobacterium tuberculosis. Antimicrob Agents Chemother 2007;51:1380-5.

[16] Grant S, Kaufmann BB, Chand NS, Haseley N, Hung DT. Eradication of bacterial persisters with antibiotic-generated hydroxyl radicals. Proc Natl Acad Sci U S A 2012;109:12147-52.

[17] Grosset JH, Singer TG, Bishai WR. New drugs for the treatment of tuberculosis: hope and reality. Int J Tuberc Lung Dis 2012;16:1005-14.

[18] Xu J, Lu Y, Fu L, Zhu, Wang B, Mdluli K, et al. In vitro and in vivo activity of clofazimine against Mycobacterium tuberculosis persisters. Int J Tuberc Lung Dis 2012;16:1119-25.

[19] Cholo MC, Boshoff HI, Steel HC, Cockeran R, Matlola NM, Downing KJ, et al. Effects of clofazimine on potassium uptake by a Trk-deletion mutant of Mycobacterium tuberculosis. J Antimicrob Chemother 2006;57:79-84.

[20] Heifets LB, Lindholm-Levy PJ. Bacteriostatic and bactericidal activity of ciprofloxacin and ofloxacin against Mycobacterium tuberculosis and Mycobacterium avium complex. Tubercle 1987;68:267-76.

[21] O'Toole GA. Microtiter dish biofilm formation assay. J Vis Exp 2011;47:2437.

[22] Kulka K, Hatfull G, Ojha AK. Growth of Mycobacterium tuberculosis biofilms. J Vis Exp 2012;60:3820

[23] Stepanovic SI, Cirkovic LR, Svabic-Vlahovic M. Biofilm formation by Salmonella spp. and Listeria monocytogenes on plastic surface. Lett Appl Microbiol 2004;38:428-32.

[24] Irwin SM, Gruppo V, Brooks E, Gilliland J, Scherman M, Reichlen MJ, et al. Limited activity of clofazimine as a single drug in a mouse model of tuberculosis exhibiting caseous necrotic granulomas. Antimicrob Agents Chemother 2014;58:4026-34.

[25] Yano T, Kassovska-Bratinova S, Teh JS, Winkler J, Sullivan K, Isaacs A, et al. Reduction of clofazimine by mycobacterial type $2 \mathrm{NADH}$ :quinone oxidoreductase: a pathway for the generation of bactericidal levels of reactive oxygen species. J Biol Chem 2011;286:10276-87. 
[26] Orenstein EW, Basu S, Shah NS, Andrews JR, Friedland GH, Moll AP, et al. Treatment outcomes among patients with multidrug-resistant tuberculosis: systematic review and metaanalysis. Lancet Infect Dis 2009;9:153-61.

[27]Dey T, Brigden G, Cox H, Shubber Z, Cooke G, Ford N. Outcomes of clofazimine for the treatment of drug-resistant tuberculosis: a systematic review and meta-analysis. J Antimicrob Chemother 2013;68:284-93.

[28] Gopal M, Padayatchi N, Metcalfe JZ, O'Donnell MR. Systematic review of clofazimine for the treatment of drug-resistant tuberculosis. Int J Tuberc Lung Dis 2013;17:1001-7.

[29] Shim TS, Jo K-W. Medical treatment of pulmonary multidrug-resistant tuberculosis. Infect Chemother 2013;45:367-74.

[30] Grosset JH, Tyagi S, Almeida DV, Converse PJ, Li SY, Ammerman NC, et al. Assessment of clofazimine activity in a second-line regimen for tuberculosis in mice. Am J Respir Crit Care Med 2013;188:608-12. 